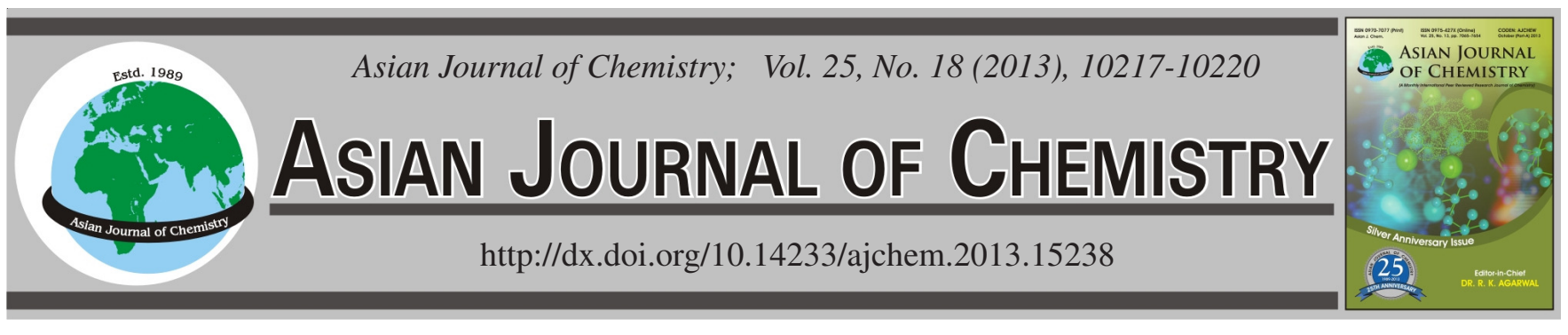

\title{
Simultaneous Cadmium(II)/Phenol Removal from Water by Mixed Micellar-Enhanced Ultrafiltration Using Brij 35/SDS
}

\author{
BAOWEI ZHAO*, JiNGYUAN RAN and JiNKUI ZHONG
}

School of Environmental and Municipal Engineering, Lanzhou 730070, P.R. China

*Corresponding author: Fax: +86 931 4956017; E-mail: baoweizhao@mail.lzjtu.cn

\begin{abstract}
Micellar-enhanced ultrafiltration (MEUF) using single sodium dodecyl sulfate (SDS) was extensively investigated in the wastewater treatment. The present study was based on micellar-enhanced ultrafiltration using mixed Brij 35/SDS to deal with imitated waste water containing cadmium(II) ions and phenol at low concentrations. The critical micelle concentration (CMC) of mixed Brij 35/SDS was detected by conductivity method. In micellar-enhanced ultrafiltration process, the feed mixed surfactant concentration, molar ratio of Brij35 to SDS and cadmium(II) and phenol concentrations in the permeate were investigated while the rejection efficiency and the permeate flux were evaluated. With the molar ratio of Brij 35 to SDS improved, the CMCs of mixed Brij 35/SDS were much less than that of pure SDS. The rejection efficiency of cadmium changed slightly while that of phenol increased with the molar ratio when the initial SDS concentrations were kept as 1, 2 and $3 \mathrm{mmol} / \mathrm{L}$. Given 0.5 molar ratio of Brij 35 to SDS, the cadmium(II) and phenol rejection were both enhanced with the total surfactant concentration. It is concluded that the compositions of mixed anionic/nonionic surfactant should be considered in the micellar-enhanced ultrafiltration for combined polluted waste water according to the concentration level of inorganic and organic compounds.
\end{abstract}

Key Words: Micellar-enhanced ultrafiltration, Sodium dodecyl sulfate, Brij 35, Cadmium, Phenol.

\section{INTRODUCTION}

A physico-chemical method, micellar-enhanced ultrafiltration (MEUF), has been employed to remove dissolved multivalent ions or organics at low concentrations from waste stream. When surfactants are added into polluted water, a large number of multivalent metal ions are attracted onto micelle surface and the organic molecules are trapped into interior of micelles when surfactant concentration is larger than its critical micelle concentration $(\mathrm{CMC})$ with forming micelles ${ }^{1-3}$ and then the micelle-bound contaminants are rejected by the ultrfiltration membrane. Micellar-enhanced ultrafiltration is able to remove heavy metal ions and organics at low concentration efficiently.

Consumption of large quantities of surfactant and high anionic surfactant concentration in effluent occur because the current micellar-enhanced ultrafiltration are mainly based on the application of single anionic surfactant such as sodium dodecyl sulfate (SDS) and only emphasized on organic solutes or removal of heavy metal ions ${ }^{2-4}$. Thus, the operating costs will be increased significantly and secondary pollution will be caused. To our best of knowledge, few studies have been conducted on the simultaneous removal of organic and metal ions using mixed surfactants in micellar-enhanced ultrafiltration operation $^{5-7}$. The utilization of surfactant mixtures may take the advantages of some special properties, for example, attraction by anionic surfactant to cation ions and much partitioning by nonionic one to organic molecules, in order to operate the process more efficiently and economically. Micellarenhanced ultrafiltration process depends completely upon the micelle formation. In this study, the effects of mixed surfactant system Brij 35/SDS on the removal of cadmium and phenol were investigated and finally the feasibility of micellarenhanced ultrafiltration for the simultaneous removal of combined contamination was tested.

\section{EXPERIMENTAL}

All reagents were of analytical purity. Sodium dodecyl sulfate $\left(\mathrm{C}_{12} \mathrm{H}_{25} \mathrm{OSO}_{3} \mathrm{Na} ; 288 \mathrm{~g} / \mathrm{mol}\right.$; CMC $\left.1586 \mathrm{mg} / \mathrm{L}\right)$ was obtained from Tokyo Kasei Kogyo Co. Ltd., Japan. Brij 35 $\left[\mathrm{C}_{12} \mathrm{H}_{25}\left(\mathrm{OCH}_{2} \mathrm{CH}_{2}\right)_{23} \mathrm{OH} ; 1200 \mathrm{~g} / \mathrm{mol} ; \mathrm{CMC} 65.71 \mathrm{mg} / \mathrm{L}\right]$ was supplied by Acros Organics, USA. The wastewater was prepared from $\mathrm{Cd}\left(\mathrm{NO}_{3}\right)_{2} \cdot 4 \mathrm{H}_{2} \mathrm{O}$ and phenol (Tianjin Guangfu Chemical Factory, China). The deionized water was used in all experiments. The hollow fiber ultrafiltration membrane (UEOS-503) was used, which was offered by Tianjin Motian 
Membrane Technology Co., Ltd., China. The membrane material is made from polysulfone, with $6000 \mathrm{Da}$ of MWCO, $1.5 \mathrm{~m}^{2}$ of the effective area in $50 \mathrm{~mm} \times 386 \mathrm{~mm} \times 50 \mathrm{~mm}$ glass column, $0-0.15 \mathrm{MPa}$ of the operating pressure and 2-13 of the operating $\mathrm{pH}$ values.

Determination of critical micelle concentration (CMC): The conductivity method was used to determine CMC value at room temperature. The plots of specific conductivitysurfactant concentration yielded two straight lines with different slopes. The intersection of two straight lines on the plot was the CMC of the surfactant.

Procedure: The experimental apparatus and procedure are largely the same as reported in our previous study ${ }^{8}$. When the effect of mixed surfactant composition on rejection was concerned, the feed tank was initially filled with $4 \mathrm{~L}$ of imitated waste water containing $50 \mathrm{mg} / \mathrm{L} \mathrm{Cd}^{2+}$ and $50 \mathrm{mg} / \mathrm{L}$ phenol, in which the concentration of SDS was kept as 1,2 or $3 \mathrm{mmol} / \mathrm{L}$ and the various ratios of Brij35/SDS were kept as $0.1,0.2$, $0.3,0.5,0.7,1.0$ and 2.0. When the effect of mixed surfactant concentration on rejection was concerned, the feed tank was also filled with $4 \mathrm{~L}$ of prepared waste water containing $50 \mathrm{mg} / \mathrm{L}$ $\mathrm{Cd}^{2+}$ and $50 \mathrm{mg} / \mathrm{L}$ phenol, in which the molar ratio of Brij 35/ SDS was kept as 0.5 and the total surfactant concentration changed from 0 to $3000 \mathrm{mg} / \mathrm{L}$. The solution was shaken adequately and standing for $3 \mathrm{~h}$, then peristaltically pumped cross the ultrafiltration apparatus at $0.07 \mathrm{MPa}$ and room temperature. The permeate stream was sampled at the desired interval and the permeate flux was calculated from the permeate volume. The concentration of cadmium ions was measured by AA110/220 flame atomic absorption spectrophotometer (Varian, USA). The concentration of phenol was determined with 4-amino antipyine spectrophotometric method at $510 \mathrm{~nm}$ by UV-752 spectrophotometer (Shanghai Spectrum Instrumental Co., China). After each operation, the membrane was washed by the solutions as followed, $0.1 \mathrm{~mol} / \mathrm{L} \mathrm{NaOH}, 1 \%$ citric acid, $1 \% \mathrm{NaClO}$ and distilled water for 15 min until $\mathrm{pH}$ value of effluent became neutral and the flux of membrane recovered. The membrane washing procedure was operated at a pressure of $0.03 \mathrm{MPa}$.

Removal efficiency of cadmium or phenol (R, \%) was defined as

$$
\mathrm{R}=\frac{\mathrm{C}_{\mathrm{f}}-\mathrm{C}_{\mathrm{p}}}{\mathrm{C}_{\mathrm{f}}}
$$

and the permeate flux $\left(\mathrm{J}, \mathrm{L} / \mathrm{m}^{2} \mathrm{~h}\right)$ was calculated as

$$
\mathrm{J}=\frac{\mathrm{V}}{\mathrm{S} \cdot \mathrm{t}}
$$

where $C_{p}(m g / L)$ is the solute concentration in the permeate and $\mathrm{C}_{\mathrm{f}}(\mathrm{mg} / \mathrm{L})$ is the solute concentration in the feed solution, respectively; $\mathrm{V}(\mathrm{L})$ is the permeate volume, $\mathrm{S}\left(\mathrm{m}^{2}\right)$ is the effect area of membrane and $\mathrm{t}(\mathrm{h})$ is the time.

\section{RESULTS AND DISCUSSION}

Critical micelle concentration: Fig. 1 shows the variation of conductivity of mixed surfactant solutions with the total surfactant concentration (taking 0.3 of molar ratio of Brij 35 to SDS as example). The conductivity increased with surfactant concentration in the aqueous phase. The CMCs could be

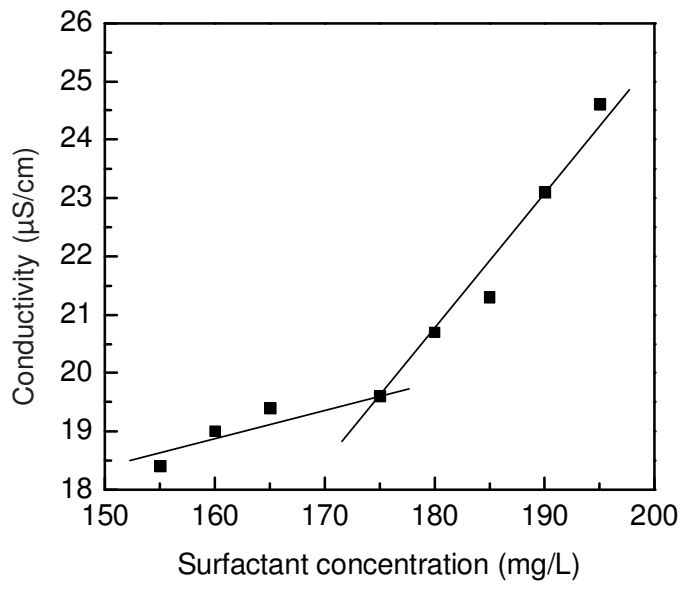

Fig. 1. Variation of conductivity of mixed Brij 35/SDS at 0.3 of molar ratio with total surfactant concentration

obtained by the inflection point of curves (for example, CMC of 0.3 Brij 35/SDS was $175 \mathrm{mg} / \mathrm{L}$ ). As shown in Table-1, the $\mathrm{CMC}$ value of pure SDS was $1586 \mathrm{mg} / \mathrm{L}$ and those of mixed Brij 35/SDS at the molar ratio 0.1, 0.2, 0.3, 0.5, 0.7, 1.0 and 2.0 sharply decreased from 500 to $30 \mathrm{mg} / \mathrm{L}$. Obviously, the addition of a nonionic surfactant (Brij 35) resulted in much reduction in CMC of anionic surfactant (SDS). Moreover, the more fraction of nonionic surfactant in mixed system, the less CMC values the mixed surfactant had. This indicated that the micelles could form at low surfactant concentration and the concentration of anionic surfactant in permeat could be decreased if the mixed anionic/nonionic surfactant was used in micellar-enhanced ultrafiltration. The heads of nonionic surfactant could balance the charge of ionic hydrophilic groups and thus reduced the electrical repulsion in the Stern layer of mixed micelles ${ }^{1,5,7,9}$. Meanwhile, the hydrocarbon chains of surfactant molecules have hydrophobic interaction, which drove the aggregation of surfactant molecules to form mixed micelles at low surfactant concentration. As a result, the CMC of surfactant decreased significantly.

\begin{tabular}{ccccccccc}
\multicolumn{1}{c}{ TABLE-1 } \\
CMC VALUES OF MIXED BRIJ 35/SDS \\
AT DIFFERENT MOLAR RATIOS \\
\hline Molar ratio & 0 & 0.1 & 0.2 & 0.3 & 0.5 & 0.7 & 1.0 & 2.0 \\
\hline CMC $(\mathrm{mg} / \mathrm{L})$ & 1586 & 500 & 265 & 175 & 145 & 90 & 65 & 30 \\
\hline
\end{tabular}

Effect of molar ratio on ultrafiltration: Fig. 2 shows the relationship between cadmium ion and phenol rejections and the molar ratios of mixed Brij 35/SDS, given 1, 2 and 3 $\mathrm{mmo} / \mathrm{L}$ of feed SDS concentration, respectively. The removal efficiency of cadmium increased slightly and then decreased within the tested molar ratios while the initial concentration of SDS was a constant ( 2 or $3 \mathrm{mmol} / \mathrm{L}$ ). This was somewhat similar to the previous results ${ }^{7}$. Huang et al. ${ }^{7}$ found an optimal molar ratio at which the rejection of cadmium ions was maximum. On the one hand, the addition of Brij 35 caused decrease in CMC. Thus, the number of micelles increased, which enhanced more cadmium ions attracted by the micelles. On the other hand, as the molar fraction of Brij 35 in the micelles increased, the charge density of mixed Brij 35/SDS micelles decreased and thus the counter ion binding ability of 


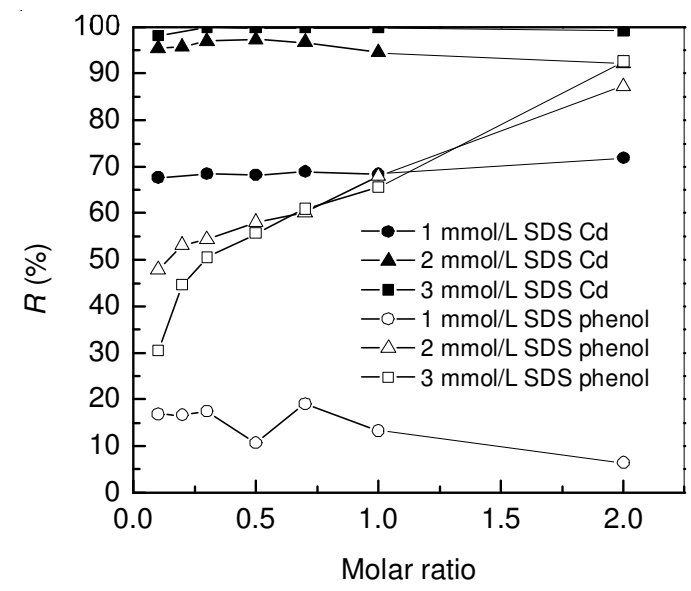

Fig. 2. Effect of molar ratio of Brij 35/SDS on removal efficiencies of cadmium and phenol

micelles weakened. This had negative effect on rejection of cadmium ions. As the two opposite effects reached equilibrium, the cadmium ion rejection efficiency was at peak. However, the removal efficiency of cadmium significantly increased with the concentration of SDS from 1 to $3 \mathrm{mmol} / \mathrm{L}$. For example, given $1 \mathrm{mmol} / \mathrm{L}$ of SDS concentration and 0.3 of the molar ratio of Brij 35/SDS, the permeate cadmium concentration was $14.9 \mathrm{mg} / \mathrm{L}$ and the removal efficiency was $67 \%$; given 2 or $3 \mathrm{mmol} / \mathrm{L}$ of SDS concentration and 0.3 of the molar ratio of Brij 35/SDS, the removal of cadmium was sharply increased to more than 95 or $97 \%$. No doubt, cations are rejected by anionic species of micelles through electrostatic attraction. More SDS addition leads to the number of micelles and the surface charges of micelles increase. Thus, the rejection efficiency improved with addition of SDS.

As for the removal of phenol, the situation was largely different from that for cadmium. Given $1 \mathrm{mmol} / \mathrm{L}$ of the initial SDS concentration, the removal efficiencies of cadmium ions were less than $20 \%$ and did not increase with the molar ratio of Brij 35/SDS, which could be attributed to weak solubilization for phenol by mixed Brij 35/SDS due to the low surfactant concentrations and large water solubility of phenol. When the initial concentrations of SDS were 2 and $3 \mathrm{mmol} / \mathrm{L}$, respectively, the removal efficiencies of phenol increased obviously with the molar ratio of Brij 35/SDS. For example, the removal efficiencies of phenol increased from 47.8 to $87.3 \%$ when the molar ratio of Brij 35/SDS increased from 0.1 to 2.0 given 2 $\mathrm{mmol} / \mathrm{L}$ of the initial concentration of SDS, while those from 37.4 to $93.9 \%$ given $3 \mathrm{mmol} / \mathrm{L}$ of the initial concentration of SDS. The soluble organics are mainly rejected by partitioning into the interior of micelles. In general, the capability of solubilization by a nonionic surfactant is larger than that by an anionic surfactant ${ }^{10}$. Therefore, the capability of solubilization by mixed anionic/nonionic surfactant is better than that of single anionic one if the dosages of surfactants are equal ${ }^{11}$. The more fraction of nonionic surfactant in mixed system, the larger the capability of solubilization of mixed surfactant. Meanwhile, in most cases, the synergism solubilization is observed when an anionic surfactant is mixed with a nonionic one ${ }^{11}$, which also enhanced the removal of phenol. As shown in Fig. 2, a large amount of Brij 35 would be needed if a high removal of phenol was expected.
In practice, the combined polluted waste water, such as waste water containing heavy metal ions and organics, is common. To remove the contaminants simultaneously by micellar-enhanced ultrafiltration, some surfactants could be chosen. It is invalid to remove heavy metal ions if a single nonionic surfactant is used. The micelles of an anionic surfactant have the ability to attract cations and to partition organic molecules. However, as mentioned above, due to its large CMC and low solubilization capability for organics, a large amount of surfactant would be needed and high surfactant concentration in the permeate solution would occur. Therefore, the mixed anionic/nonionic surfactants would be an alternative. The composition and dosage of mixed surfactant depend upon the concentration levels of heavy metal ions and organic solutes in waste water.

The variation of permeate fluxes with the molar ratios of Brij35 to SDS given 1, 2 and $3 \mathrm{mmol} / \mathrm{L}$ of SDS is shown in Fig. 3. The permeate fluxes decreased from 4.43 to $3.89 \mathrm{~L} / \mathrm{m}^{2} \mathrm{~h}$ in $1 \mathrm{mmol} / \mathrm{L}$ SDS system, from 6.81 to $2.40 \mathrm{~L} / \mathrm{m}^{2} \mathrm{~h}$ in $2 \mathrm{mmol} /$ L SDS system and from 5.79 to $1.97 \mathrm{~L} / \mathrm{m}^{2} \mathrm{~h}$ in $3 \mathrm{mmol} / \mathrm{L}$ SDS system, which demonstrated the permeate fluxes decreased sharply when SDS concentrations were high and did slightly when SDS concentrations were low, with the Brij35/SDS molar ratio increasing. Because the CMCs of mixed surfactants decreased with an increase in molar fraction of Brij35, the number of micelles in solution increased. Thus, a large number of micelles could be formed and adsorbed on the surface of membrane $e^{9,12,13}$. This resulted in a decrease of the permeate fluxes. The addition of Brij35 also led to decrease in the permeate fluxes. Taking into account of permeate flux, higher operation pressure would be required if the mixed anionic/ nonionic surfactants were used in micellar-enhanced ultrafiltration process.

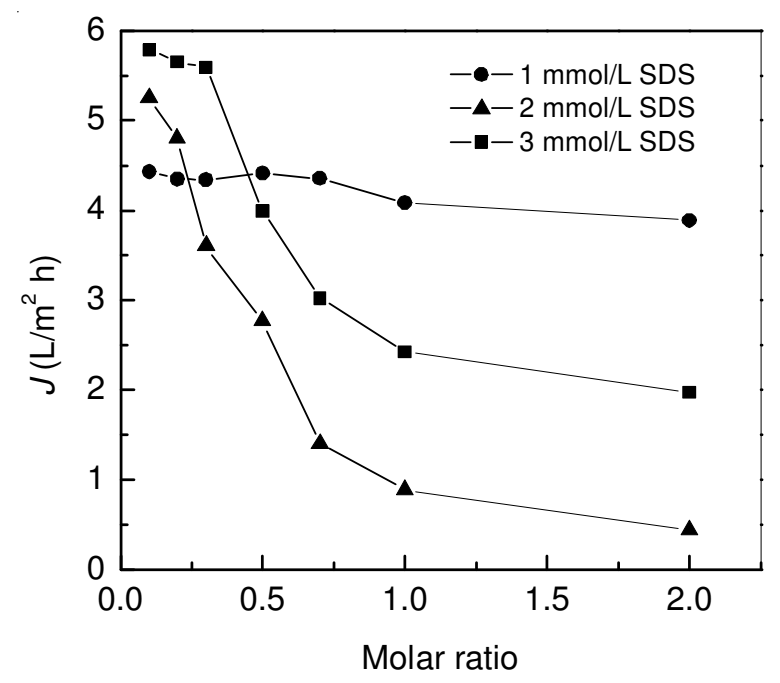

Fig. 3. Effect of molar ratio of Brij 35/SDS on permeate flux

Effect of mixed surfactant concentration on ultrafiltration: To investigate the effect of mixed Brij 35/SDS concentration on ultrafiltration, 0.5 Brij 35/SDS was chosen and its concentrations changed from 0 to $3000 \mathrm{mg} / \mathrm{L}$. As shown in Fig. 4, both cadmium and phenol rejection efficiencies increased at large with the mixed surfactant concentration and then leveled off. These trends were similar to those when a 


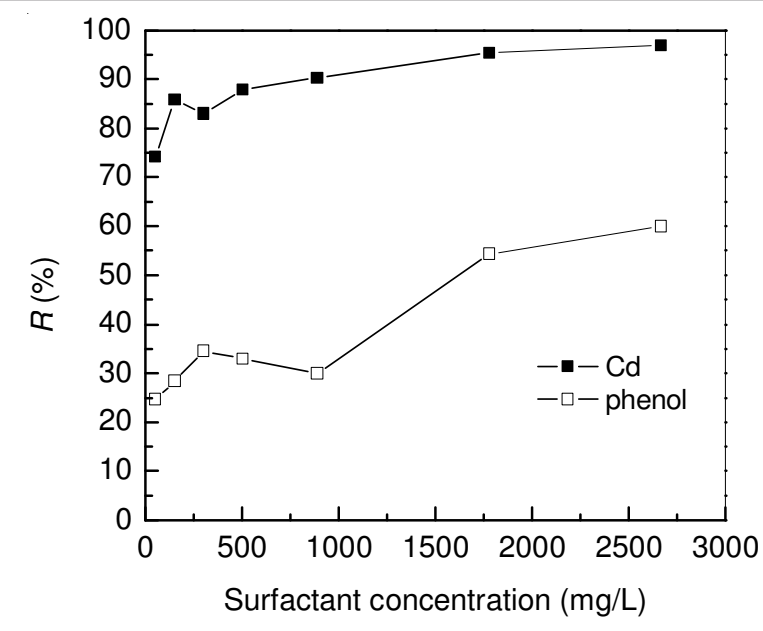

Fig. 4. Effect of mixed Brij 35/SDS concentration on removal efficiencies of cadmium and phenol

single anionic surfactant was used in micellar-enhanced ultrafiltration. The cadmium and phenol rejection were 75 and $25 \%$, respectively when a little amount of mixed Brij 35/SDS $(50 \mathrm{mg} / \mathrm{L})$ was added. At $2700 \mathrm{mg} / \mathrm{L}$ of the mixed surfactant concentration, over $96 \%$ cadmium and $60 \%$ phenol were removed. Obviously, the rejection of pollutants depended upon the mixed surfactant concentration if the composition of mixed surfactant was given.

\section{Conclusion}

The critical micelle concentrations of mixed Brij 35/SDS were much less than that of pure SDS and decreased with the molar fraction of Brij 35 in mixed surfactant. The rejection efficiency of cadmium changed slightly while that of phenol increased with the molar ratio of Brij 35 to SDS when SDS concentration ranged from 1 to $3 \mathrm{mmol} / \mathrm{L}$. Given 0.5 molar ratio of Brij 35 to SDS, both cadmium(II) and phenol rejection were enhanced with the total surfactant concentration. The composition and concentration of mixed anionic/nonionic surfactant should be considered in the micellar-enhanced ultrafiltration for combined polluted waste water.

\section{ACKNOWLEDGEMENTS}

This work was financially supported by the Science and Technology Development Program of Lanzhou City (2011-1$41)$ and the Program for Changijang Scholars and Innovative Research Team in University (IRT0966).

\section{REFERENCES}

1. C.C. Tung, Y.M. Yang, C.H. Chang and J.R. Maa, Waste Manage., 22, 695 (2002).

2. B. Rahmanian, M. Pakizeh and A. Maskooki, J. Hazard. Mater., 184, 261 (2010).

3. P. Yenphan, A. Chanachai and R. Jiraratananon, Desalination, 253, 30 (2010).

4. L. Ghezzi, B.H. Robinson, F. Secco, M.R. Tiné and M. Venturini, Colloids Surf. A, 329, 12 (2008).

5. X. Li, G.M. Zeng, J.H. Huang, D.M. Zhang, L.J. Shi, S.B. He and M. Ruan, Desalination, 276, 136 (2011).

6. G.M. Zeng, X. Li, J.H. Huang, C. Zhang, C.F. Zhou, J. Niu, L.J. Shi, S.B. He and F. Li, J. Hazard. Mater., 185, 1304 (2011).

7. J.H. Huang, G.M. Zeng, Y.Y. Fang, Y.H. Qu and X. Li, J. Membr. Sci., 326, 303 (2009).

8. B. Zhao, J. Xu, W. Li, H. Wang and H. Che, Asian J. Chem., 23, 1509 (2011).

9. J.H. Huang, G.M. Zeng, K. Xu and Y.Y. Fang, Trans. Nonferrous Met. Soc. China, 15, 184 (2005).

10. D.E. Kile and C.T. Chiou, Environ. Sci. Technol., 23, 832 (1989).

11. B. Zhao, L. Zhu, W. Li and B. Chen, Chemosphere, 58, 33 (2005).

12. C.K. Liu and C.W. Li, Sep. Purif. Technol., 43, 25 (2005).

13. M. Aoudia, N. Allal, A. Djennet and L. Toumi, J. Membr. Sci., 217, 181 (2003) 